\title{
Does Catheter ablation for Premature Ventricular Contractions remain unsuccessful in Arrhythmogenic Right Ventricular Cardiomyopathy?
}

\author{
Erdi Babayiğit ${ }^{1}$, Andaç Karadeniz ${ }^{2}$, Kadir Uğur Mert ${ }^{3}$, and Bulent Gorenek ${ }^{3}$ \\ ${ }^{1}$ Kulu State Hospital \\ ${ }^{2}$ Hinıs Public Hospital \\ ${ }^{3}$ Eskisehir Osmangazi University
}

April 11, 2021

\begin{abstract}
We have read with great interest the article "Efficacy of Catheter Ablation for Premature Ventricular Contractions (PVC) in Arrhythmogenic Right Ventricular Cardiomyopathy (ARVC)" by Assis F.R. et. al. PVC ablation in ARVC was previously studied by Aras D. et al and they presented successful results.In this study, we believe that the study should not be considered as unsuccessful since 2 patients showed a decrease in PVC burden by more than $80 \%$ and in the other three patients between 45-70\%. The demonstration of a decrease in PVC burden with catheter ablation in ARVD patients indicates that a second ablation may increase the success rate and decrease symptoms. The fact that ARVC has a complex substrate and the disease can progress is undoubtedly the most important factor in achieving the desired success with PVC ablation. Epicardial ablation with endocardial ablation has increased the chance of success in this patient group. In addition, given that BCSD ablation and basal heart rate are guaranteed by ICD implantation, we think that administration of the maximum dose of antiarrhythmic medication may create a significant improvement in these patients. And another factor, contact force sensing plays an important role in evaluating the effectiveness of the process. We suggest that with the current treatment modalities, a pharmacoablative combination therapy and re-ablation when necessary would be appropriate for such a complicated disease.
\end{abstract}

Does Catheter ablation for Premature Ventricular Contractions remain unsuccessful in Arrhythmogenic Right Ventricular Cardiomyopathy?

Erdi Babayiğit ${ }^{1}$, MD; Andaç Karadeniz ${ }^{2}$, MD; Associate Professor Kadir Uğur Mert ${ }^{3}$, MD; Professor Bülent Görenek ${ }^{3}$, MD, FACC, FESC

${ }^{1}$ Kulu State Hospital, Department of Cardiology, Kulu, Konya, Turkey

${ }^{2}$ Hinıs Public Hospital, Department of Internal Medicine, Erzurum, Turkey

${ }^{3}$ Eskişehir Osmangazi University, Faculty of Medicine, Department of Cardiology, Eskişehir, Turkey

Corresponding Author:

Erdi Babayigit, MD Kulu State Hospital, Kulu, Konya, Turkey Phone: + 9033264161 00, Mobile phone: +905357409486 E-mail:erdibabayigit@gmail.com, erdi.babayigit@saglik.gov.tr

Funding: None

Conflict of Interest: None 
We have read with great interest the article "Efficacy of Catheter Ablation for Premature Ventricular Contractions (PVC) in Arrhythmogenic Right Ventricular Cardiomyopathy (ARVC)" by Assis F.R. ${ }^{1}$ et. al and thanks for the authors for their contribution to the literature. We would like to point out a few points to be considered about their study.

As they have stated, the small number of patients is insufficient to determine the exact role of PVC ablation in ARVC. However, PVC ablation in ARVC was previously studied by Aras D. ${ }^{2}$ et al. and they presented successful results. Aras D. et al. showed a significant decrease in PVC burden and improvement in ventricular tachycardia storm in ARVC patients with endocardial and epicardial ablation in a series of 17 patients with successful catheter ablation.

In this study, we believe that the study should not be considered as unsuccessful since 2 patients showed a decrease in PVC burden by more than $80 \%$ and in the other three patients between $45-70 \%$. The demonstration of a decrease in PVC burden with catheter ablation in ARVD patients indicates that a second ablation may increase the success rate and decrease symptoms.

The fact that ARVC has a complex substrate and the disease can progress is undoubtedly the most important factor in achieving the desired success with PVC ablation. In this instance, especially epicardial ablation with endocardial ablation has increased the chance of success in this patient group. In addition, given that bilateral cardiac sympathetic denervation ablation and basal heart rate are guaranteed by ICD implantation, we think that administration of the maximum dose of antiarrhythmic medication may create a significant improvement in these patients. As another factor, contact force sensing plays an important role in evaluating the effectiveness of the process.

As a result, we suggest that with the current treatment modalities, a pharmacoablative combination therapy and re-ablation when necessary would be appropriate for such a complicated disease.

Assis FR, Sharma A, Daimee UA, et al. Efficacy of Catheter Ablation for Premature Ventricular Contractions in Arrhythmogenic Right Ventricular Cardiomyopathy [published online ahead of print, 2021 Mar 30]. $J$ Cardiovasc Electrophysiol . 2021;10.1111/jce.15025. doi:10.1111/jce.15025

Aras D, Özcan F, Çay S, Özeke Ö, Kara M, Topaloğlu S. Endo/epicardial ablation of ventricular arrhythmias with contact force-sensing catheters in arrhythmogenic right ventricular dysplasia/cardiomyopathy. Anatol J Cardiol . 2019;21(4):187-195. doi:10.14744/AnatolJCardiol.2018.58534 